\title{
MAQUIAVEL E A FENOMENOLOGIA DAS CONJURAÇÕES: APONTAMENTOS DE LEITURAS E HIPÓTESES INTERPRETATIVAS ${ }^{1}$
}

\begin{abstract}
ALESSANDRO CAMPI ${ }^{2}$
RESUMO: O tema das conspirações é frequentemente utilizado nos trabalhos de Maquiavel. Para isso, aliás, ele dedicou um dos seus mais famosos capítulos dos Discursos (III, 6). Não obstante, histórias de intriga e conspiração perpassam as histórias do Florentino, como em seus "escritos da chancelaria diplomática". Observando a literatura predominante, "tem-se falado de maneira inapropriada sobre conspirações políticas e maquinações em $O$ Príncipe (XIX) e nos textos histórico-políticos. Diferente de outros autores clássicos, a partir de Sallustio, Maquiavel não se limitou a descrever conspirações. Por meio de uma forma muito peculiar de enfrentamento, Maquiavel construiu uma verdadeira teoria ou fenomenologia, de um modo jamais alcançado por outros pensadores. Ele classificou as conspirações, identificadas em suas diversas variações históricas, desvelando-as em sua dimensão técnico-operacional, ilustrando as fases e os métodos de desenvolvimento, as motivações ideais, as justificativas materiais e as matrizes sociológicas. Além disso, ele apresentou uma chave da interpretação eminentemente histórica e política. Isso precisa ser salientado porque, durante muito tempo, essas interpretações limitaram-se às motivações psicológicas dos conspiradores.
\end{abstract}

PALAVRAS-CHAVE: Maquiavel, Conspirações, Fenomenologia, Teoria Política.

ABSTRACT: The theme of conspiracies is frequently used in the works of Machiavelli. Moreover, he dedicated one of the most famous chapters of the Discourses to it (III, 6). But also, stories of intrigue and conspiracy continually run through in the Florentine Histories as in his diplomatic-chancery writings. Looking at the predominant literature, it's been spoken inaccurately of political plots and machinations in the Prince (XIX) as in his minor historicalpolitical texts. Unlike other classical authors, from Sallustio onwards, Machiavelli did not limit himself to describing single conspiracies. For this particular and extreme form of struggle Machiavelli has offered a true theory or phenomenology, something that other thinkers had never achieved. He classified the conspiracies, identified the various historical variations, has shed light on the technical-operational dimension, illustrated the phases and the methods of development, the ideal motivations, the material justifications and the sociological matrices. Above all, he has offered a key of interpretation eminently historical and political. This deserves to be highlighted because for a long time these interpretations were limited to the psychological reasons of the conspirators.

KEYWORDS: Machiavelli, Conspiracies, Phenomenology, Political theory.

\footnotetext{
${ }^{1}$ Traduzido por Brunello Natale de Cusatis.

2 Professor do Departamento de Ciência Política da Università degli Studi di Perugia. E-mail: alessandro.campi@unipg.it
} 
A bibliografia crítica sobre Nicholas Maquiavel está notoriamente exterminada. Todos os aspectos do seu trabalho e da sua vida foram sondados, fazendo deles um objeto de análises minuciosas (embora nem sempre convincentes). Tanto que, ao percorrer os escritos maquiavelianos, é difícil identificar um tema ou um argumento que ainda não tenha sido amplamente encarado por estudiosos dos mais diversos países. Hoje, aqueles que querem escrever e refletir sobre Maquiavel estão expostos ao risco de serem repetitivos e banais. Temos a impressão de que, se não tudo, certamente o essencial, já tenha sido dito.

Mas, olhando com atenção, verifica-se que há partes da sua biografia e sua produção intelectual que ainda não foram suficientemente esclarecidas e sobre as quais as pesquisas científicas têm ainda algo a dizer. Pensemos só nas escassas notícias, que ainda hoje temos, relacionadas à sua juventude e sua formação. Maquiavel nasceu em 1469 e morreu em 1527. Sobre a segunda parte da sua existência temos muita informação, especialmente a partir de 1498: o ano em que, apenas cinco dias após o assassínio de Savonarola, ele foi eleito para chefiar a segunda chancelaria da República de Florença. Mas, quanto aos seus primeiros vinte e nove anos ainda sabemos muito pouco: a tal ponto que ninguém conseguiu explicar de forma convincente, por que um jovem que não era um letrado famoso, nem um doutor em direito, cuja família não pertencia à nobreza da cidade e não tinha riquezas ou papéis públicos particulares, foi capaz de obter um cargo político-administrativo tão importante. Que relações sociais e políticas tinha o jovem Maquiavel? A que grupo de poder pertencia? Quais eram os seus sentimentos políticos e por qual tipo de experiência de vida ele tinha passado? Por quais leituras e autores foi influenciado, considerando que ele não tinha seguido um percurso de estudo regular? São perguntas às quais nenhum biógrafo - nem mesmo o mais célebre e escrupuloso, Roberto Ridolfi (1978) - conseguiu responder de forma exaustiva e convincente. Talvez as respostas para estas questões ainda se encontrem à espera de ser descobertas em algum documento perdido num arquivo.

Mas há outro pequeno mistério histórico que deveria ser esclarecido, sempre com referência à sua vida, mais do que ao seu pensamento. É o que tem a ver com a aparência física de Maquiavel. Qual era a sua cara? Como seria, exatamente, o seu rosto e a sua fisionomia? Pode parecer uma questão supérflua e irrelevante. Afinal, há muitos autores do passado que só conhecemos através de retratos inventados, falsos ou distorcidos: quem pode dizer que conhece a verdadeira imagem de Platão, Cícero ou Santo Agostinho? Mas, no caso de Maquiavel, essa dúvida sobre as suas verdadeiras feições apresenta um aspecto histórico-crítico particularmente delicado. Isso deve-se ao fato de que os seus retratos canônicos - começando pelo mais famoso 
e difundido, a pintura guardada no Palazzo Vecchio, em Florença, e atribuída a Santi di Tito (1536-1603) - terem, por mais diferentes que sejam entre eles, uma característica comum: mostram-nos o autor de $O$ Príncipe com traços e expressões que podem definir-se "maquiavelianas". Por outras palavras, eles mostram-nos Maquiavel exatamente como esperamos que Maquiavel deveria ser, considerando a má reputação que sempre o acompanhou: a boca pequena com os lábios cerrados, a fronte espaçosa e inteligente, o olhar pungente e interrogativo, o sorriso irônico e sarcástico, uma expressão facial astuta e maliciosa. Trata-se do Maquiavel real, como os seus contemporâneos o viram e conheceram, ou da imagem póstuma e estereotipada do Maquiavel autor maldito e descobridor das inexoráveis leis do poder, assim como este último se enraizou no imaginário popular praticamente até hoje?

A partir desta última pergunta, a pista de pesquisa que deveria ser seguida diz respeito à possibilidade de que os retratos de Maquiavel, em particular os dos séculos XVI e XVII, fossem realmente a variante iconográfica do anti-maquiavelismo político-filosófico e literário. Trata-se de uma perspectiva de estudo, que abrange a historiografia política e a história da arte, que, até agora, não foi encarada de uma maneira sistemática (CAMPI, 2014). Pessoalmente, proporcionei uma primeira contribuição nessa direção, estudando todas as diferentes variantes de um dos retratos mais conhecidos de Maquiavel: a chamada "Testina", que apareceu, pela primeira vez, em 1540-41 numa colecção das suas obras publicada em Veneza pela editora Comin da Trino (CAMPI, 2019). É um retrato de Maquiavel, claramente falso e arbitrário, cuja fortuna ao longo dos séculos, de acordo com a interpretação que propus, deve-se aos traços luciferinos e perturbadores com os quais o autor de $O$ Príncipe era apresentado aos seus leitores com o objetivo de alertar estes últimos dos maus ensinamentos que teriam recebido. Em suma, um exemplo de anti-maquiavelismo confiado, no entanto, não à força persuasiva da escrita, mas ao poder evocativo da imagem.

Mas sobre a reconstrução e interpretação do pensamento de Maquiavel, tal como mencionado, ainda há espaços para estudo e aprofundamento. Embora seja verdade que a força dos clássicos nos faça crer que qualquer um possa lê-los a seu gosto - encontrando neles sempre novos estímulos intelectuais ou novas perspectivas críticas que dependem da conjuntura histórica - também é verdade que os estudiosos, às vezes, seguindo modas político-culturais, tendem a concentrar-se obsessivamente em certos aspectos ou temas, deixando de fora outros. Pensemos só na quantidade de literatura crítica que se acumulou nas últimas três décadas - a partir das clássicas pesquisas de Hans Baron, J. G. A. Pocock e Quentin Skinner - sobre Maquiavel como fautor das virtudes republicanas. Por outro lado, pensemos no pouco que tem 
sido escrito, por exemplo, sobre um assunto que, pelo contrário, ocorre frequentemente nos seus escritos e sobre o qual, aqui, gostaríamos de chamar a atenção.

\section{As conjurações e a luta pelo poder na Itália renascentista}

Referimo-nos, particularmente, ao Maquiavel teórico e estudioso das conjurações: entendidas como uma modalidade de luta pelo poder recorrente na história (especialmente na época renascentista) e, portanto, merecedor de uma elaboração doutrinária autónoma. De fato, os relatos e as descrições de conjurações, complôs e maquinações secretas ocorrem com frequência nos escritos maquiavelianos, particularmente na correspondência epistolar diplomática-administrativa e nas Histórias de Florença. Em confirmação de que se tratava de um tema ao qual ele atribuía uma grande importância e para o qual ele nutria um profundo interesse. Mas é sobretudo nos Discursos - no célebre capítulo 6, do livro III - que o tema das conjurações é encarado por Maquiavel de forma sistemática e com a ambição de oferecer, ao mesmo tempo, uma ampla casuística histórica (tirada do mundo clássico e da história italiana mais próxima a ele), uma classificação de modo geral, uma elaboração conceitual e um exame técnico.

Trata-se de uma seção da obra, intitulada, precisamente, Das conjurações, que sempre impressionou leitores e críticos em virtude do seu comprimento incomum. Presume-se, portanto, que ela deva ser considerada como um tratado autónomo, que com frequência gozou de circulação e difusão independente, já atestada pela tradição manuscrita. Dos códigos utilizados para realizar as modernas edições críticas dos Discursos, na verdade, dois compõemse de transcrições - distintas, embora provavelmente descendentes de um antepassado comum, ambas que remontam à primeira metade do século XVI - precisamente do capítulo sobre as conjurações: o código Palatino 1104, cc. 45r-56v, da Biblioteca Nacional de Florença e o manuscrito X de Balia, Carteggio, Responsive 119, cc. 290-319, do Arquivo de Estado de Florença. O que sugere que esta parte dos Discursos tem sido lida como uma obra à parte desde os anos logo após a sua composição e que pode ter sido objeto de discussão durante as reuniões nos Orti Oricellari, frequentadas por Maquiavel entre 1516 e 1519.

Mas é na França que, algumas décadas após a morte de Maquiavel, se inaugura uma tradição que tende precisamente a considerar as reflexões deste último sobre as conjurações, como um texto independente que pela escabrosidade da matéria tratada - a conquista do poder ou a eliminação do inimigo político através do homicídio, a sedição de uma minoria organizada 
contra a ordem estabelecida - por um lado, se relaciona com a literatura clássica sobre o tema das conspirações políticas e do tiranicídio; por outro, parece apresentar mais conexões com $O$ Príncipe (onde o assunto é encarado no capítulo XIX, com base em formulações muito semelhantes às contidas nos Discursos) do que com a sua obra sobre as repúblicas (no interior da qual de fato figura como uma digressão anómala). Em 1575, por exemplo, aparece em Paris, publicada por Abel l'Angelier, uma versão do Bellum Catilinae de Sallustio, realizada por Jérôme de Chomedey que apresenta como apêndice a tradução em francês do Traicté des coniurations, extraict du troisiesme livre des discours de Machiavel, que é, precisamente, uma extrapolação dos Discursos do capítulo sobre as conjurações. Em 1822, sempre em Paris, surge, através do editor Chassériau, uma tradução anônima do Príncipe, cujo apêndice contém o tratado Des conspirations. Em 1842, o Traité des conspirations et du régicide (que inclui, ao lado do sexto capítulo, também a tradução francesa do sétimo e oitavo capítulos sempre do terceiro livro dos Discursos) aparece como última seção (depois do Traité de la République e do Traité du Prince, ou de la Monarchie) das (Euvres politiques de Machiavel impressas em Paris por Lavigne Libraire-Éditeur e editadas por P. Christian, que nos permite, como guia à leitura, um Essai sur l'esprit révolutionnaire. A tradução utilizada é a clássica realizada por Charles Guiraudet, em 1799, para a sua edição das Euvres de Machiavel, que será retomada em meados do século XX, na França em 1935 e na Bélgica em 1944, em duas edições de $O$ Príncipe, que no apêndice também reproduzem o Traité des conspirations et du régicide, precisamente, na versão que já tinha aparecido em 1842.

Uma escolha de considerar como independente o capítulo sobre as conjurações dos Discursos que, de maneira mais ocasional, também tem sido feita em outros contextos linguísticos. Na Itália do "Risorgimento", um trecho deste último aparece no Elettuario contro le sette segrete publicado em Modena, em 1853, pela Tipografia Vincenti: uma denúncia do conspiracionismo maçônico-carbonário de marca católica e contrarrevolucionária que utiliza Maquiavel para mostrar quais perigos e fracassos atendem os que se unem contra a ordem estabelecida. Na íntegra, foi publicado numa edição portuguesa do panfleto maquiaveliano que apareceu em 1945, em Lisboa, pela editora Cosmos, com tradução de Berta Mendes e prefácio e notas de Manuel Mendes: o título deste apêndice para $O$ Príncipe, Tratado das Conspirações e do Regicídio e uma leitura rápida do mesmo denunciam, de maneira muito clara, a dependência desta versão lusitana da francesa de Guiraudet mencionada anteriormente. Em 2010, o capítulo Das conjurações foi publicado em inglês sob o título On Conspiracies, juntamente com outros trechos dos Discursos que apresentam uma afinidade - na verdade nem 
sempre direta - com o tema (há também uma versão em espanhol publicada em 2012). Uma coleção comentada de todos os textos maquiavelianos que se referem às conjurações (além do capítulo dos Discursos também o capítulo XIX de O Príncipe, o escrito sobre o Tradimento del Duca Valentino... e os vários episódios de conjurações presentes nas Histórias de Florença) finalmente apareceu na Itália já em 2014, traduzida para o inglês em 2018 (MACHIAVELLI, 2014; CAMPI, 2018). Não obstante esse interesse editorial, a impressão é que o tema ainda não foi adequadamente desenvolvido ao nível crítico-interpretativo, ${ }^{3}$ apesar da importância que tinha para o próprio Maquiavel: no plano teórico, mas também, como sabemos, por razões biográficas e pessoais. ${ }^{4} \mathrm{O}$ que se segue constitui apenas um conjunto de ideias e reflexões que pretendem demonstrar exatamente a relevância do tema e a necessidade de aprofundá-lo em termos de pesquisa textual e interpretação histórica.

\section{Um esquema de classificação e interpretação das conjurações}

Lendo com atenção, o capítulo Das conjurações contido nas Histórias abre-se com uma contradição evidente, deixada sem solução por Maquiavel. Uma característica indicativa da sua forma de argumentar, muitas vezes marcada por incongruências lógicas, exageros ou manipulações na reconstrução de fatos, os quais são, todavia, funcionais ao desenvolvimento do seu discurso político. Se, por um lado, sustenta-se que devido a complôs e conspirações se tem visto "muito mais príncipes ter perdido a vida e o Estado do que por guerra aberta" (III, 6, 3) - o que pareceria atestar a sua eficácia à luz da experiência histórica antiga, e a ele contemporânea -, por outro lado, argumenta-se que as conjurações representam um tipo de empreendimento que é "difícil e muito perigosa na sua totalidade; de onde deriva que muitas se vão experimentando e muito poucas alcançam o objetivo desejado" (III, 6, 4). Um ceticismo sobre a utilidade prática-política de tal instrumento de luta que se encontra expresso, com palavras semelhantes, também em $O$ Príncipe ("as dificuldades que estão do lado dos conspiradores são infinitas e, por experiência, nota-se que as conjurações foram muitas e que poucas tiveram bom êxito”, XIX, 11) e que pode ser explicado - vista a data de composição de

\footnotetext{
${ }^{3}$ Uma das poucas exceções é a do estudo, pioneiro em muitos sentidos, de Elena Fasano Guerini (1996). Veja também as obras de Bento (2013) e Polansky, Schillinger (2018).

${ }^{4}$ Referimo-nos ao envolvimento pessoal de Maquiavel, pelo menos, em dois episódios de conjurações: aquela de fevereiro de 1513, orquestrada por Pier Paolo Boscoli e Agostino Capponi com o objectivo de assassinar Giuliano di Lorenzo de' Medici e aquela de junho de 1522 promovida por alguns descendentes da aristocracia florentina (estudantes e amigos de Maquiavel) e que tinha como objetivo o cardeal Giulio de' Medici (o futuro papa Clemente VII). Trata-se, na realidade, de dois episódios muito controversos, para os quais nunca foi comprovada, através de documentos e fontes históricas concretas, a participação direta de Maquiavel.
} 
ambos os textos, notoriamente sucessiva à remoção de Maquiavel do cargo de chanceler em novembro de 1512 e que não pode ser estendida além de 1517 - recordando a sua experiência traumática de Fevereiro de 1513, quando ele se viu envolvido, contra a sua vontade, num efêmero complô conspiratório (concebido por Pietro Paolo Boscoli e Agostino Capponi contra Giuliano de' Medici e já citado em nota) que lhe custou algumas semanas de prisão e tortura. Daí também os convites à prudência e a atitude quase fatalista com que o capítulo parece abrirse: se aos príncipes vai ser aconselhado, para escapar do perigo sempre à espreita de conjurações, a buscar e manter por qualquer meio o favor do povo (ser "odiado pelo universo inteiro" à razão das ofensas trazidas "nos bens, no sangue ou na honra" dos súditos e pelas ameaças dirigidas a estes últimos representa, de fato, a causa principal dos complôs conspiratórios), pelo contrário, aos particulares (ou seja, aos cidadãos individuais) - tentados a intrometer-se numa prática que Maquiavel considera efêmera e pouco realista, pelo mero fato de ser concebida e realizada por uma camarilha ou um pequeno grupo - é dirigido o convite "a contentar-se com o viver debaixo daquele poder que pelo destino tem sido proposto a eles" (um aviso que se reporta ao que está contido também em $O$ Príncipe, III, 1, 1: “os homens mudam de bom grado de senhor, convencidos que vão melhorar e esse convencimento faz com que eles empunhem as armas contra o seu antigo senhor: mas estão enganados, porque logo depois a experiência vai demonstrar que eles escolheram para pior").

Mas a desaprovação ou a aversão verdadeira por esse tipo de empreendimento não impede Maquiavel de propor, tal como mencionado, um tratamento analítico, dada a sua frequência no contexto político da época e considerando a importância atribuída a elas na historiografia greco-romana, tão assiduamente tratada por ele.

Em primeiro lugar, há que fazer uma distinção entre as conjurações "contra um príncipe" (a que é dedicada à maioria das suas reflexões e que implica uma simples mudança na liderança do poder), àquelas "contra a pátria" (que perseguem, pelo contrário, uma mudança constitucional, a vontade de passar de uma república ou monarquia corrupta para o principado - como no exemplo de Catilina, historicamente paradigmático, mesmo no seu fracasso - e brevemente tratadas apenas no final do capítulo) e aquelas "que realizam para dar uma terra aos inimigos que a assediam" (já analisadas nos Discursos, II, 32, 16-24).

Esclarece-se então o que se deve entender por conjurações, prestando fé à sua etimologia latina (cum-iurare): um ato coletivo baseado no vínculo de um juramento, distinto da ação individual ou do clássico tiranicídio ("Não se pode dizer que seja conjuração, mas é uma firme disposição de matar o príncipe por parte de um homem”, III, V, 27). 
Por fim, especifica-se como o pressuposto sociológico das conjurações - as do primeiro tipo - é representado pela proximidade física dos conspiradores com o príncipe, isto é, por pertencer ao seu círculo ou por ter "fácil acesso" (III, 6, 38) ao poder ("Digo que, segundo as histórias, todas as conjurações são realizadas por homens nobres ou familiares do príncipe", III, 6, 36; "Vê-se, portanto, que aqueles que conspiraram têm sido todos homens nobres ou familiares do príncipe", III, 6, 41); enquanto o pressuposto psicológico há de se encontrar principalmente na ingratidão e na "cupidez de dominar" (III, 6, 46) por parte dos que, tendo obtido do príncipe todo tipo de privilégio e vantagem, acabam por ambicionar a sua posição, à custa da sua própria eliminação (como aqueles conspiradores romanos - aduzidos por exemplo no texto - dos seus imperadores e protetores "constituídos em tanta riqueza, honra e poder que parecia que a perfeição da sua grandeza carecera de algo diferente do Império", III, 6, 42).

A partir dessas premissas, Maquiavel presta particular atenção aos aspectos técnicooperativos das conjurações, confirmando a orientação amiúde pragmática e instrumental do seu pensamento e o fato de que, por mais arriscados que sejam, as conjurações podem, sob determinadas condições, ser coroadas por sucesso e representar uma modalidade, se não legítima, em alguns casos necessária ou útil, para a mudança política e nos equilíbrios do poder. Daí seguem conselhos práticos, regras e receitas, sobre como evitar os perigos e contratempos que as conjurações implicam e sobre as medidas para neutralizá-las ou concretizá-las, que parecem ser direcionadas, indiferentemente, tanto aos príncipes como aos "homens particulares" e que, ao longo dos séculos, acabaram por consagrar essas célebres páginas como uma sorte de manual para homens de poder e aspirantes conspiradores, redigido com uma intenção quase pedagógica (considerando-se pervertida ou edificante conforme o ponto de vista dos leitores).

As dificuldades que, na visão de Maquiavel, comportam as conjurações relacionam-se com as três diferentes fases técnicas do seu desenvolvimento: "há perigo em manuseá-las, em executá-las e uma vez executadas" (III, 6, 25), elas apresentam complicações "antes, no momento dos fatos e depois" (III, 6, 51). Na fase inicial, a da idealização, o problema é manter o segredo, sobretudo se este for compartilhado entre muitos sujeitos ("Poderás encontrar um ou dois de confiança; mas como tu contas com muitos, é impossível encontrá-los” III, 6, 57). O risco, na medida de quanto se vai estendendo a rede dos participantes do complô, é o da delação ou traição, ou seja, da imprudência ("quando um conspirador fala dele com pouca cautela", III, $6,62)$. Por isso, é preciso, por parte de quem seja o artífice ou o promotor, revelar o seu plano subversivo só às pessoas realmente confiáveis ou melhor a ninguém e, em qualquer caso, só na 
altura de passar à ação; e isso também serve para não dar tempo para ser denunciado e não deixar provas das suas intenções que possam resultar sendo comprometedoras. (Mas é preciso ter presente a glosa, por assim dizer técnica, contida em outro famoso escrito maquiaveliano, a Vita di Castruccio Castracani: "nessas coisas [nas conjurações] se o número reduzido é suficiente para manter o segredo, não é suficiente para a execução").

No que diz respeito à execução, as dificuldades surgem, pelo contrário, "ou por uma mudança de planos; ou pela falta de ânimo por parte de quem vai executá-la; ou por erro do executor devido à pouca prudência; ou por não dar perfeição à coisa, permanecendo em vida parte daqueles que se planeava matar" (III, 6, 100). A atuação de uma conjuração, sempre que não seja descoberta com antecedência, deve lidar, em suma, com os imprevistos e o caso, os quais baralham o plano preconcebido e obrigam a variá-lo no último momento, com a imperfeição ou falta de sangue frio dos atacantes, com a pouca prudência com que, às vezes, se escolhem os objetivos (como quando se pretende eliminar duas pessoas ao mesmo tempo) e com a reação raivosa de quem tem a sorte de sobreviver à emboscada.

Quanto aos perigos que se correm na terceira fase, uma vez completada a conjuração, eles reduzem-se a um: "no caso haja alguém disposto a vingar o príncipe morto" (III, 6,153), tanto maior será ele se "o povo é amigo do príncipe que tu mataste». Assim, Maquiavel chega ao ponto talvez central da sua argumentação, o que fornece coerência teórica a toda à sua reflexão e justifica politicamente a sua aversão pessoal a esta forma de luta: se é o ódio popular contra o príncipe que cria o humor coletivo (portanto as condições e a justificação) que leva os "homens nobres" a conspirar, é o favor do povo, por outro lado, o melhor antídoto para os complôs subversivos, se for verdade - como se lê também em $O$ Príncipe - que contra um príncipe que seja "reputado", "excelente" e "venerado" "se conjura com dificuldade" (XIX, 5). Se as conjurações são, do ponto de vista operativo, um fenômeno por definição elitista e socialmente restrito que se consome na esfera do poder, entre os poucos que o possuem e os poucos que aspiram a detê-lo, do qual o povo é, portanto, excluído, este último é, no entanto, o árbitro que decreta, para além do alcance ou não do objetivo imediato de qualquer conjuração individual, 0 sucesso real ou o fracasso concreto do ponto de vista político. Os conspiradores que depois de ter matado o príncipe não conseguem ganhar o favor do povo, talvez brandindo instrumentalmente a bandeira da liberdade ou da tirania, estão condenados ao fracasso e expostos à sua vingança.

A conclusão, afirma Maquiavel, é que, seja como for, as conjurações são perigosas para o príncipe, mesmo que a intenção de o matar falhe. Se elas lançam sempre uma sombra de 
infâmia sobre quem as organiza, de qualquer maneira, deixam uma sombra de suspeita também sobre quem tem sido a vítima. Mais ainda se o príncipe, depois de ter escapado aos sicários ou ter descoberto e neutralizado o plano criminoso, conseguiu matá-los e persegui-los junto com seus cúmplices: o povo, com efeito, acaba por crer "que tenha sido [a conjuração] uma invenção daquele príncipe para desafogar a sua avareza e crueldade contra a vida e os bens daqueles que matou" (III, 6, 186).

\section{As conjurações em perspectiva histórica: a lição dos clássicos e a lição da experiência}

Conforme o referido, alguns dos argumentos sobre as conjurações desenvolvidos nos Discursos encontram-se sucintamente expostos (antecipados ou retomados?) também na parte inicial do capítulo XIX do Príncipe (De contemptu et odio fugiendo), entre os mais discutidos pela crítica por causa da sua estrutura desarmônica e pouco coerente, fruto de evidentes reconstruções e conspícuas integrações: a vacuidade das conjurações como meio para reverter as estruturas de poder; a dificuldade dos conspiradores para encontrar cúmplices leais, motivados e não dispostos a trair por conveniência; a recomendação ao príncipe, de cunho utilitarista, de evitar "ser odiado ou desprezado" e de manter "o povo satisfeito com ele" (XIX, 9) para conter as ambições dos "homens nobres" e evitar que conspirem contra ele. Um aspecto que Maquiavel submete à verificação histórica através de uma ampla casuística, extraída, em grande parte, da obra de Herodiano e referida à vida dos imperadores romanos da época da dinastia Severa, cada um dos quais - desde Commodo a Maximino, o Trácio, passando por Antonino Caracalla e Alessandro Severo - foi artífice e vítima de complôs causados pela impossibilidade de satisfazer, simultaneamente, a ganância dos soldados que os apoiavam com armas e a sede de poder dos nobres, generais e cortesãos que os rodeavam, bem como por não terem assegurado nunca o apoio popular. Mas há também outras fontes históricas-literárias clássicas das quais Maquiavel tem sacado exemplos históricos de conjurações, começando com Heródoto (CAMPI, 2016b).

Mas é sobretudo em História de Florença que devemos procurar os exempla que apoiem a visão maquiaveliana das conjurações e que, referindo-se a eventos históricos mais vinculados à sua experiência política direta e ao seu conhecimento das cortes principescas, em certa medida enriquecem a sua interpretação. As conjurações, mesmo à luz das dinâmicas conflituais que marcaram a história de Florença desde as suas origens, são apresentadas nesta obra como um fenômeno tendencialmente desagregador e corrosivo, do qual não emerge uma nova ordem política, pelo contrário uma instabilidade perene, fruto, a sua vez, de um sentimento de ódio e 
vingança entre as facções e as partes, destinado a durar no tempo e a minar a vida civil (este é o valor atribuído à conjuração nobiliária encabeçada em Florença, em 1340, por Piero de Bardi e Bardo Frescobaldi: II, 32). Portanto, elas são típicas daqueles contextos históricos, como o da Itália do século XV, em que ainda não se tinham definido de maneira permanente as estruturas institucionais e de poder. Ao mesmo tempo, é dada mais atenção do que nos Discursos - basta pensar nos relatos da conspiração organizada por Stefano Porcari, em 1453 (VI, 29), e daquela que em 1476 custou a vida a Galeazzo Maria Sforza (VII, 33-34) - às motivações ideais das conjurações (a glória, a honra, a defesa das liberdades, a luta contra a tirania ou o obscurantismo religioso), que diferem, portanto, do entrelaçamento dos interesses econômicos, ambições de poder, disputas entre facções e ressentimentos privados que constituíam a sua causa principal, bem exemplificados na História de Florença, por episódios como a conjuração contra Annibale Bentivoglio de 1445 (VI, 9-10), a sedição contra Piero de' Medici de 1466 (VII, 20-10) e a conjuração dos Pazzi de 1478 (VIII, 1-10).

\section{Um labirinto de palavras}

Que o fenômeno conspiratório não seja unívoco no seu significado político e nas suas modalidades operacionais também é demonstrado pelo fato de que para descrevê-lo Maquiavel recorre não só ao termo conjuração, mas a um conjunto mais articulado de palavras e expressões que utiliza como sinônimos. Ao mesmo tempo, a palavra conjuração nos seus escritos por vezes é usada também num sentido figurado e metafórico, ou seja, para indicar situações ou contextos diferentes do homicídio por razões políticas. A constelação semântica que indica as conjurações em sentido próprio inclui termos que podem considerar-se equivalentes no seu significado, como "conspirações" ("sem que os seus cidadãos tiveram conspirado nunca contra ele", $O$ Príncipe, VIII, 22), “acordos” (“os florentinos, por acordo, tiraram-lhe Pisa”, Histórias, II, 30, 10; "ordenou [...] certo acordo", carta aos Dez de Liberdade de 7 de Outubro de 1502), "intrigas" ("realizou intrigas em Cortona para levá-la aos Florentinos", Histórias, II, 30, 10), "maquinações" ("todos eles maquinavam e tramavam contra sua Excelência”, carta aos Dez de Liberdade de 20 de Outubro de 1502) e "inteligências" ("dizem-me todos que esta é uma inteligência de certeza com Pandolfo", carta aos Dez de Balia de 11 de Abril de 1505). Mas encontram-se também, especialmente nos escritos de cancelaria, "raciocínios", "ligas" e "seitas". Pelo contrário, Maquiavel não recorre ao termo "complô", porque é um lema de matriz francesa que entrou na linguagem política só a partir do século XVII. 
Quanto aos significados transladados, nos Discursos II, 2, 40 "uma conjuração de repúblicas" é sinónimo de uma liga ou aliança político-militar, bem como uma "conjuração feita”, no Príncipe XIII, 8, indica um acordo ou entendimento em detrimento de alguém. Mas conjurar também é empregado por Maquiavel, como no uso linguístico de hoje, para indicar a conjunção de forças ou eventos múltiplos em direção ao mesmo objetivo ("para destruir um Império tão poderoso [...] não foi somente uma população, mas muitas foram aquelas que [...] conjuraram": Histórias, I, 1, 4).

Mesmo essa digressão terminológica não deve ser considerada como um fim em si mesmo: a partir do uso que Maquiavel faz de diferentes termos e do significado que ele atribui ao fenômeno das conjurações tiram-se importantes considerações teóricas, úteis para refletir sobre o significado atual desses fenômenos e para distinguir conceitualmente entre as conjurações em sentido próprio (entendidas como fato político) e a conspiração entendida, pelo contrário, como mentalidade e filosofia da história. Os escritos de Maquiavel, portanto, fornecem ideias úteis para interpretar a política contemporânea, como tentamos fazer em alguns dos nossos trabalhos dedicados propriamente à distinção - histórica e teórica - entre conjurações e complôs (CAMPI, 2016a).

\section{Um legado controvertido}

Ao longo dos séculos, as páginas maquiavelianas sobre as conjurações tiveram excelentes leitores, os quais, muitas vezes, se encontraram envolvidos pessoalmente em tramas e desenhos subversivos: desde Etienne Pasquier a Tommaso Campanella, desde os doutrinários da Razão de Estado a Gabriel Naudé, desde o Cardeal de Retz aos patriotas-conspiradores do "Risorgimento" italiano que absorveram e muitas vezes adaptaram os preceitos e ensinamentos técnicos dessas páginas. Quanto à crítica contemporânea, ela, pelo contrário - tal como mencionado -, parece ter negligenciado esse aspecto da reflexão de Maquiavel: tem-se limitado a esclarecer que ele era um adversário determinado das conjurações, por causa das suas desventuras biográficas e pelo fato de considerá-las muito perigosas e, portanto, improdutivas. Há, no entanto, exceções a essa linha interpretativa, mesmo muito diferentes umas das outras. Um importante historiador do pensamento político como Rodolfo De Mattei, por exemplo, tem enfatizado as páginas sobre as conjurações, sendo estas últimas a demonstração exemplar do grande interesse de Maquiavel pelo lado técnico-operativo dos fenômenos políticos, a partir de uma orientação essencialmente empírica-naturalista e uma atitude prática-instrumental. Da 
maneira asséptica com que Maquiavel se ocupa das conjurações resultaria, portanto, o "gosto clínico do estudioso dos fatos políticos, unicamente interessado na representação objetiva de um evento na sua nua e inelutável realidade fenomênica" (DE MATTEI, 1969, p.63). Uma leitura similar, quase coeva, é a realizada pelo historiador americano Felix Gilbert. De acordo com De Mattei, também Gilbert está convencido que o capítulo dos Discursos sobre as conjurações seja o melhor exemplo da atitude fundamentalmente racionalista e utilitarista de Maquiavel que considera os homens movidos, unicamente, pelos seus interesses egoísticos: "Minimizando os motivos ideais das tentativas de matar um tirano, ele chega à conclusão que as conjurações não têm alguma probabilidade de sucesso, porque todos, pensando antes de tudo à sua própria salvação e aos seus próprios interesses, no momento em que surgem os inevitáveis perigos das conjurações, buscam salvar-se à custa dos outros” (GILBERT, 1970, p. 136).

Pelo contrário, a interpretação de Leo Strauss, compartilhada pelos principais expoentes da sua escola a partir de H. C. Mansfield Jr., resulta, decisivamente, excêntrica. Também para Strauss a reflexão maquiavélica sobre as conjurações deveria ser considerada paradigmática e altamente expressiva, mas desde uma perspectiva muito particular. Esta não confirmaria nem o carácter cínico e amoral dos seus ensinamentos, nem a redução da arte política à mera técnica de governo; mais mostraria o verdadeiro objetivo de toda a sua obra: liquidar a Grande Tradição da filosofia clássico-cristã e o modelo de ordem política que surgiu desta última. Maquiavel, por ser um mestre das conjurações, nunca perdeu tempo conspirando contra os poderosos seus contemporâneos, mas dedicou-se a uma trama mais vasta de inspiração histórico-ideal, a uma conjuração metafísica e meta-histórica dirigida contra o cristianismo e a civilização clássica, na qual ele teria intentado envolver a juventude do seu tempo, propondo a essa última o sonho de um renascimento espiritual inspirado nos valores do paganismo antigo. A organização, com as únicas armas do intelecto, desta grandiosa conjuração espiritual - que nada tem a ver com as conjurações para o poder, relativamente às quais Maquiavel se limitou a propor uma análise do ponto de vista técnico para demonstrar a sua substancial ineficácia - teria sido o verdadeiro legado do Secretário florentino à história: do seu sucesso - conclui Strauss - tem surgido, de fato, aquela Modernidade que ainda hoje venera Maquiavel (STRAUSS, 1958).

Estes são apenas alguns exemplos, mas que, todavia, justificam a nossa ideia segundo a qual em Maquiavel é possível rastrear uma verdadeira teoria geral ou fenomenologia das conjurações, bem como a nossa convicção de que Maquiavel, por muito estudado e aprofundado que seja, é um autor que ainda pode reservar-nos algumas surpresas. Basta saber buscar na direção certa e, quando necessário, sair das pistas de pesquisa mais batidas e consolidadas. 


\section{REFERÊNCIAS BIBLIOGRÁFICAS}

BENTO, António (2013), "Das Conjuras. Análise de um Capítulo de Discursos Sobre a Primeira Década de Tito Livio”, Res Publica (Porto), n. 13, pp. 63-78.

CAMPI, Alessandro (2014), "Iconografia”, Enciclopedia Machiavelliana, Roma: Istituto della Enciclopedia Italiana, vol. II, pp. 744-751.

CAMPI, Alessandro (2016a), Congiura o complotto? Una distinzione analiticamente $e$ storiograficamente necessaria, in Alessandro Campi, Leonardo Varasano (eds.), Congiure e complotti. Da Machiavelli a Beppe Grillo, Soveria Mannelli: Rubbettino, pp. 21-36.

CAMPI, Alessandro (2016b), Una fonte machiavelliana in materia di cospirazioni e trame segrete: Erodoto e la congiura dei sette contro il falso Smerdi, in Alessandro Campi, Leonardo Varasano (eds.), Congiure e complotti. Da Machiavelli a Beppe Grillo, Soveria Mannelli: Rubbettino, pp. 101-128.

CAMPI, Alessandro (2018), Machiavelli and Political Conspiracies. The Struggle for Power in the Italian Renaissance, London-New York: Routledge.

CAMPI, Alessandro (2019), “A (false) portrait of Machiavelli and the origins of iconographic anti-Machiavellism: genesis, fortunes, and propagation of 'La Testina"', History of Political Ideas, DOI: 10.1080/01916599.2018.1559751.

DE MATTEI, Rodolfo (1969), Dal premachiavellismo all'antimachiavellismo, Sansoni: Firenze.

FASANO GUARINI, Elena (1996), Congiure «contro alla patria» e congiure «contro ad uno principe» nell'opera di Niccolò Machiavelli, in Yves-Marie Bercé, Elena Fasano Guarini (eds.), Complots et conjurations dans l'Europe moderne, Roma: École française de Rome, pp. 9-53.

GILBERT, Felix (1970), Machiavelli e Guicciardini, Torino: Einaudi.

MACHIAVELLI, Niccolò (2014), Sulle congiure, Note, commento e introduzione di Alessandro Campi, Soveria Mannelli. Rubbettino.

POLANSKY, David, Schillinger, Daniel, "With Steel or Poison: Machiavelli on Conspiracy", Interpretation. A Journal of Political Philosophy, Vol. 45, pp.67-86.

RIDOLFI, Roberto (1978), Vita di Niccolò Machiavelli, Firenze: Sansoni.

STRAUSS, Leo (1958) Thoughts on Machiavelli, Glencoe: The Free Press. 